\title{
Recruitment Maneuver in Prevention of Hypoxia During Percutaneous Dilational Tracheostomy: Randomized Trial
}

\author{
Federico Franchi MD, Lucia Cubattoli MD, Agnese Faltoni MD, \\ Sabino Scolletta MD, Elena Falciani MD, Egidio Mastrocinque MD, \\ Pierpaolo Giomarelli MD, and Nicoló Patroniti MD
}

\begin{abstract}
BACKGROUND: Percutaneous dilational tracheostomy (PDT) can potentially lead to hypoxia and alveolar derecruitment. The aim of this prospective study was to evaluate the efficacy of performing a recruitment maneuver (RM) before tracheostomy, in order to improve oxygenation. METHODS: We enrolled 29 eligible trauma patients with acute lung injury criteria requiring tracheostomy in a university ICU. Subjects were ventilated on volume controlled mechanical ventilation (tidal volume of $6 \mathrm{~mL} / \mathrm{kg}$ ) and $\mathrm{F}_{\mathrm{IO}_{2}}$ set at 1.0. Subjects were randomized into 2 groups: RM group (subjects who underwent RM 10 min before PDT, 15 subjects) and no-RM group (subjects without application of RM before PDT, 14 subjects). RM was performed by imposition of continuous positive airway pressure of $40 \mathrm{~cm} \mathrm{H}_{2} \mathrm{O}$ for 40 seconds. We collected gas exchange, respiratory, and hemodynamic data 5 times: 1 hour before RM, 5 min after RM, 5 min after PDT, 30 min after PDT, and 6 hours after PDT. RESULTS: Subjects who underwent RM had a significant increase in $\mathrm{P}_{\mathrm{aO}_{2}}$; 5 min after the maneuver, $\mathrm{P}_{\mathrm{aO}}$ increased from $222.6 \pm 33.4 \mathrm{~mm} \mathrm{Hg}$ to $341.3 \pm 33.1 \mathrm{~mm} \mathrm{Hg}$ $(P<.01)$ and was always significantly maintained throughout the following times of the study, compared to the no-RM group: in the RM and no-RM groups, respectively, $260.7 \pm 35.4 \mathrm{~mm} \mathrm{Hg}$ vs $108.5 \pm 36.9 \mathrm{~mm} \mathrm{Hg} 5 \mathrm{~min}$ after PDT; $285.6 \pm 29.1 \mathrm{~mm} \mathrm{Hg}$ vs $188.4 \pm 21.4 \mathrm{~mm} \mathrm{Hg} 30 \mathrm{~min}$ after PDT; and $226.3 \pm 24.8 \mathrm{~mm} \mathrm{Hg}$ vs $147.6 \pm 42.8 \mathrm{~mm} \mathrm{Hg} 6 \mathrm{~h}$ after PDT $(P<.01)$. CONCLUSIONS: Our study suggests that application of RM before PDT could be useful to avoid hypoxemia following such procedure, by reducing fall in $\mathrm{P}_{\mathrm{aO}}$ and preventing the decrease in oxygenation values below baseline at 6 hours. Key words: alveolar derecruitment; tracheostomy; recruitment maneuver; acute lung injury; hypoxemia; lung ventilation. [Respir Care 2012;57(11):1850-1856. (C) 2012 Daedalus Enterprises]
\end{abstract}

\section{Introduction}

Patients with acute lung injury (ALI) and ARDS are likely to be ventilated mechanically for a long period of

The authors are affiliated with the Department of Anesthesia and Intensive Care, University of Siena, Siena, Italy, with the exception of Dr Patroniti, who is affiliated with the Department of Anesthesia and Intensive Care, University of Milano-Bicocca, Ospedale San Gerardo Nuovo, Milano, Italy.

The authors have disclosed no conflicts of interest.

Correspondence: Federico Franchi MD, Department of Anesthesia and Intensive Care, University of Siena, Viale Bracci 1, 53100, Siena, Italy. E-mail: franchif@unisi.it.

DOI: $10.4187 /$ respcare. 01798 time, and often require percutaneous dilational tracheostomy (PDT). ${ }^{1}$ Endoscopic guidance has increased the safety of this procedure ${ }^{1}$; nevertheless, ventilator disconnection and the use of a bronchoscope potentially lead to hypercarbia, hypoxia, and alveolar derecruitment (AD) ${ }^{2-4}$ Moreover, these patients require a lung-protective ventilation

See the Related Editorial on Page 1980

strategy with low tidal volume $\left(\mathrm{V}_{\mathrm{T}}\right), 5,6$ and this contributes as well to increased AD. Recruitment maneuvers (RMs) have been introduced as an important component of lungprotective ventilation strategy. ${ }^{7,8}$ Lung volume recruitment refers to the dynamic process of opening previously collapsed lung units through a transient increase in transpul- 
monary pressure. ${ }^{9}$ The utility of RMs in increasing oxygenation and limiting $\mathrm{AD}$ has been demonstrated in patients with ALI-ARDS, ${ }^{9-14}$ during general anesthesia, mainly in some surgical procedures ${ }^{15}$ and in conditions associated with $\mathrm{AD}$, such as endotracheal suctioning ${ }^{16,17}$ or endotracheal intubation. ${ }^{18}$ On these occasions RMs were applied only after the various procedures, when $\mathrm{AD}$ had already occurred, and not in order to prevent it.

Setting RM after these procedures may not always be feasible because of patient instability (eg, bleeding, hypotension) and risks related to RM's side effects, such as hemodynamic impairment and barotrauma. ${ }^{19,20}$

The aim of the study was to evaluate the utility and reliability of RM performed before PDT, in order to improve oxygenation by preventing AD in ALI patients.

\section{Methods}

We performed a prospective randomized study in our university hospital ICU. Approval from the institutional review board was obtained, along with written informed consent from subjects or their legal representative. We enrolled 29 eligible trauma patients (18 male, 11 female) with the ALI criteria of the American-European Consensus Conference ${ }^{21}$ requiring tracheostomy. Inclusion criteria were: age over 18 years; presence of a pulmonary artery catheter; intracranial pressure $<20 \mathrm{~mm} \mathrm{Hg}$ (in patients with brain trauma); absence of active air leak (pneumothorax, subcutaneous emphysema, pneumomediastinum) and obstructive airways disease; and hemodynamic stability (defined as mean arterial pressure $>70 \mathrm{~mm} \mathrm{Hg}$ and cardiac index $>2.2 \mathrm{~L} / \mathrm{min} / \mathrm{m}^{2}$ ). ${ }^{9,22,23}$ Subjects were classified on the basis of their admission diagnosis and their comorbidities, according to the definitions of the Italian group for the evaluation of intervention in intensive care. $^{24}$

Subjects were randomized into 2 groups, using a closed envelope system: subjects who underwent RM (15 subjects) 10 min before PDT, and subjects who did not undergo RM (14 subjects). All subjects were orally intubated; sedated with propofol $2 \%(0.5-2 \mathrm{mg} / \mathrm{kg} / \mathrm{h})$ or midazolam $(0.5-2 \mu \mathrm{g} / \mathrm{kg} / \mathrm{h})$ and fentanyl $(0.5-1 \mu \mathrm{g} / \mathrm{kg} / \mathrm{h})$; paralyzed with atracurium from $60 \mathrm{~min}$ before the procedure; and equipped with radial arterial catheter, central venous catheter, and pulmonary artery catheter (7 French, Baxter, Irvine, California). Subjects were on volume controlled mechanical ventilation with a $\mathrm{V}_{\mathrm{T}}$ of $6 \mathrm{~mL} / \mathrm{kg}$ (Servo-i, Maquet, Bridgewater, New Jersey) and respiratory rate allowing the maintenance of a $\mathrm{P}_{\mathrm{aCO}} \leq 45 \mathrm{~mm} \mathrm{Hg}$. $\mathrm{F}_{\mathrm{IO}_{2}}$ was set at 1.0, and inspiration/expiration time ratio at $1: 2$ at all times of the study. PEEP was set on the basis of the inflection points of the pressure-volume (P-V) curve; in the absence of the lower inflection point, PEEP was set during an incremental PEEP trial, using the oxygenation

\section{QUICK LOOK}

\section{Current knowledge}

Bedside percutaneous dilatational tracheostomy in mechanically ventilated patients can lead to hypoxemia, resulting from loss of airway pressure and alveolar collapse.

\section{What this paper contributes to our knowledge}

Application of a recruitment maneuver prior to percutaneous tracheostomy at the bedside avoids hypoxemia immediately following the procedure and up to 6 hours after the procedure.

response as the primary end point. Intrinsic PEEP was also measured and recorded.

During PDT, subjects received $100 \%$ oxygen at maintenance PEEP, without changing the respirator's settings. PDT was always performed with a single conically formed dilator (Blue Rhino, Cook Medical, Bloomington, Indiana). ${ }^{1}$ All steps of the procedure and positioning of the tracheostomy tube were controlled bronchoscopically. Blood and secretions were removed by bronchoscopy over the tracheostomy tube prior to resumption of mechanical ventilation. Chest radiography was performed to exclude complications.

\section{Measurements}

A P-V curve of the respiratory system was performed using the multiple occlusion method, as described by Levy, ${ }^{25} 60$ min before PDT. Static pressures were recorded during a 3 second pause at end-inspiration, up to an airway pressure of $50 \mathrm{~cm} \mathrm{H}_{2} \mathrm{O}$, while $\mathrm{V}_{\mathrm{T}}$ was changed in a random order. Subjects were ventilated with a normal $\mathrm{V}_{\mathrm{T}}$ between the test breaths, just to avoid lung derecruitment. We developed the P-V curve on graph paper and we visually identified the lower inflection point. The intersection of tangents drawn to the lower flat portion and to the linear mid-portion of the curve helped to identify the lower inflection point, which corresponds to the point where the slope of the P-V curve changes abruptly. The respiratory and metabolic parameters collected were peak airway pressure, plateau pressure, PEEP, end-tidal partial pressure of $\mathrm{CO}_{2}$, quasi-static compliance of the respiratory system, arterial $\mathrm{pH}, \mathrm{P}_{\mathrm{aO}}, \mathrm{P}_{\mathrm{aCO}}$, dead space fraction $\left(\mathrm{V}_{\mathrm{D}} / \mathrm{V}_{\mathrm{T}}\right)$, and intrapulmonary shunt fraction. They were recorded $60 \mathrm{~min}$ before tracheostomy ( $1 \mathrm{~h}$ before RM), $5 \mathrm{~min}$ after RM, 5 min after mount tube exchange, 30 min after PDT, and 6 hours after PDT.

Compliance of the respiratory system and intrapulmonary shunt fraction were calculated with the conventional 
formulas. $\mathrm{V}_{\mathrm{D}} / \mathrm{V}_{\mathrm{T}}$ was estimated by rearranging the Bohr equation and assuming a respiratory quotient $=1$. At the same times, mean arterial pressure was recorded and cardiac output was calculated by thermodilution with the pulmonary artery catheter. According to randomized criteria, 15 subjects underwent RM. A unique session of RM was delivered 10 min before tracheostomy, by switching the ventilator to continuous positive airway pressure, and rapidly increasing the PEEP level up to $40 \mathrm{~cm} \mathrm{H}_{2} \mathrm{O}$ for 40 seconds. During the RM the maximum peak airway pressure tolerated was $40 \mathrm{~cm} \mathrm{H}_{2} \mathrm{O}$. The RM was stopped in case of hypotension (systolic arterial pressure $<90 \mathrm{~mm} \mathrm{Hg})^{22}$ or severe hypoxemia $\left(\mathrm{S}_{\mathrm{aO}_{2}}<80 \%\right)$. At the end of PDT, chest radiography was performed to exclude complications. Previous 24-hour fluid balance was recorded.

\section{Statistical Analysis}

Statistical analysis was performed using statistics software (SPSS 11.5, SPSS, Chicago, Illinois, and Prism 4.0, GraphPad Software, San Diego, California). We calculated that at least 7 subjects would be required in each group to allow analysis of a $50 \mathrm{~mm} \mathrm{Hg}$ increase in mean $\mathrm{P}_{\mathrm{aO}_{2}} 5$ min after PDT between 2 groups, assuming a statistical significance level of $95 \%(\alpha=.05)$ and a minimum power of $90 \%(\beta=.10)$. All data are presented as mean \pm SD or number and percentage when appropriate. To test normal distribution, the Kolmogorov-Smirnov test was used. To analyze statistical differences the independent-samples $t$ test, chi-square test, or analysis of variance for repeated measurements were used. A $P$ value less than .05 was considered statistically significant.

\section{Results}

Subject characteristics are reported in Table 1. Average intubation time before PDT and average duration of the PDT procedure were not significantly different between the 2 groups. Respiratory and hemodynamic parameters of the 2 groups at baseline are shown in Table 2; they did not show significant differences between the 2 groups. One subject needed interruption of the RM after about 2530 seconds, due to severe hypotension (systolic arterial pressure $<90 \mathrm{~mm} \mathrm{Hg}$ ) during the procedure. However, he was included in the analysis. Subjects who underwent RM (RM group) had a significant increase in $\mathrm{P}_{\mathrm{aO}_{2}} / \mathrm{F}_{\mathrm{IO}_{2}}$ (Table 3, Figure); 5 min after $\mathrm{RM}, \mathrm{P}_{\mathrm{aO}_{2}}$ increased from $222.6 \pm 33.4 \mathrm{~mm} \mathrm{Hg}$ to $341.3 \pm 33.1 \mathrm{~mm} \mathrm{Hg}(P<.01)$. The increase in $\mathrm{P}_{\mathrm{aO}}$ in the RM group was always significantly maintained throughout the following times of the study (5 min and $30 \mathrm{~min}$ after PDT, respectively, $260.7 \pm 35.4 \mathrm{~mm} \mathrm{Hg}$ and $285.6 \pm 29.1 \mathrm{~mm} \mathrm{Hg}$ ), compared to the no-RM group (5 min and $30 \mathrm{~min}$ after PDT,
Table 1. Baseline Demographic and Clinical Characteristics of Subjects

\begin{tabular}{|c|c|c|c|}
\hline & $\begin{array}{c}\text { RM } \\
(n=15)\end{array}$ & $\begin{array}{c}\text { No RM } \\
(n=14)\end{array}$ & $P$ \\
\hline Age, y & $70.2 \pm 11.6$ & $64.1 \pm 13.0$ & .19 \\
\hline Weight, kg & $79.1 \pm 11.0$ & $80.5 \pm 14.7$ & .77 \\
\hline Male, no. (\%) & $10(66.6)$ & $8(57.1)$ & .89 \\
\hline APACHE II score & $22.2 \pm 6.9$ & $21.4 \pm 5.5$ & .73 \\
\hline Days before PDT & $7.9 \pm 2.4$ & $8.3 \pm 4.9$ & .78 \\
\hline Duration of procedure, min & $21.4 \pm 9.4$ & $20.1 \pm 5.3$ & .65 \\
\hline \multicolumn{4}{|l|}{ Diagnosis of Admission, no. (\%) } \\
\hline Polytrauma & $9(60.0)$ & $8(57.1)$ & $>.99$ \\
\hline Head trauma & $5(33.3)$ & $5(35.7)$ & .79 \\
\hline Chest trauma & $1(6.6)$ & $1(7.1)$ & .49 \\
\hline \multicolumn{4}{|l|}{ Comorbidities, no. (\%) } \\
\hline Diabetes & $3(20.0)$ & $4(28.5)$ & .92 \\
\hline Hypertension & $6(40.0)$ & $7(50)$ & .87 \\
\hline Kidney failure & $1(6.6)$ & 0 & .97 \\
\hline Cardiopathy & $2(13.3)$ & $4(28.5)$ & .58 \\
\hline Arrhythmias & $1(6.6)$ & $1(7.1)$ & .49 \\
\hline None & $2(13.3)$ & $1(7.1)$ & .95 \\
\hline \multicolumn{4}{|c|}{$\begin{array}{l} \pm \text { Values are mean } \pm \text { SD. } \\
\text { RM }=\text { recruitment maneuver } \\
\text { APACHE II = Acute Physiology and Chronic Health Evaluation } \\
\text { PDT }=\text { percutaneous dilational tracheostomy. }\end{array}$} \\
\hline
\end{tabular}

respectively, $108.5 \pm 36.9 \mathrm{~mm} \mathrm{Hg}$ and $188.4 \pm 21.4 \mathrm{~mm} \mathrm{Hg}$, $P<.01)$.

Since we were interested in changes in oxygenation during the procedure, $\mathrm{P}_{\mathrm{aO}}$ values at the different times were normalized to the $1 \mathrm{~h}$ before RM values (see Figure); the fall in $\mathrm{P}_{\mathrm{aO}} 5$ min after PDT was significantly higher in the no-RM group $(55.9 \pm 14.4 \%$ in no-RM vs $37.9 \pm 14.6 \%$ in RM, $P<.01$ ) (see Figure). Five subjects in the no-RM group had a $\mathrm{P}_{\mathrm{aO}_{2}}<80 \mathrm{~mm} \mathrm{Hg} 5 \mathrm{~min}$ after PDT, and 2 of these subjects fell under a critical value of $60 \mathrm{~mm} \mathrm{Hg}$. Six hours after PDT, $\mathrm{P}_{\mathrm{aO}_{2}}$ values in the $\mathrm{RM}$ group returned similar to basal values, but were significantly higher than in the no-RM group $(226.3 \pm 24.8 \mathrm{~mm} \mathrm{Hg}$ vs $147.6 \pm 42.8 \mathrm{~mm} \mathrm{Hg}$, RM vs no-RM, respectively, $P<.01$ ) (see Table 3). The no-RM group did not achieve basal values at 6 hours after PDT $(147.6 \pm 42.8 \mathrm{~mm} \mathrm{Hg}$ vs $246.7 \pm 26.0 \mathrm{~mm} \mathrm{Hg} 6$ hours after PDT vs $1 \mathrm{~h}$ before RM in the no-RM group, $P<.01$ ) (see Table 3 ). $\mathrm{P}_{\mathrm{aCO}_{2}}$ increased in the 2 groups $5 \mathrm{~min}$ after PDT $(50.6 \pm 10.2 \mathrm{~mm} \mathrm{Hg}$ in the RM group and $46.8 \pm 4.3 \mathrm{~mm} \mathrm{Hg}$ in the no- $\mathrm{RM}$ group) and returned near to baseline values at $30 \mathrm{~min}$ after PDT (see Table 3). $\mathrm{V}_{\mathrm{D}} / \mathrm{V}_{\mathrm{T}}$ did not show significant variations in the 2 groups at the different times of the study (see Table 3). Cardiac output values, recorded at $1 \mathrm{~h}$ before RM and 5 min after RM, were not significantly different between the 2 groups. No short-term complications were observed in either group. 
Table 2. Ventilatory and Hemodynamic Parameters of the 2 Subject Groups at Baseline

\begin{tabular}{|c|c|c|c|}
\hline & $\begin{array}{c}\mathrm{RM} \\
(n=15)\end{array}$ & $\begin{array}{l}\text { No RM } \\
(n=14)\end{array}$ & $P$ \\
\hline $\mathrm{V}_{\mathrm{T}}, \mathrm{mL}$ & $496.6 \pm 61.8$ & $504.8 \pm 67.8$ & .74 \\
\hline$\dot{\mathrm{V}}_{\mathrm{E}}, \mathrm{L} / \mathrm{min}$ & $10.3 \pm 2.1$ & $10.1 \pm 1.9$ & .79 \\
\hline $\mathrm{P}_{\text {plat }}, \mathrm{cm} \mathrm{H}_{2} \mathrm{O}$ & $26.2 \pm 1.8$ & $25.6 \pm 1.5$ & .34 \\
\hline $\mathrm{P}_{\text {peak }}, \mathrm{cm} \mathrm{H}_{2} \mathrm{O}$ & $29.1 \pm 2.6$ & $28.6 \pm 2.1$ & .58 \\
\hline Intrinsic PEEP, $\mathrm{cm} \mathrm{H}_{2} \mathrm{O}$ & $2.1 \pm 1.9$ & $1.8 \pm 1.6$ & .65 \\
\hline Applied PEEP, $\mathrm{cm} \mathrm{H}_{2} \mathrm{O}$ & $12.6 \pm 2.7$ & $12.4 \pm 2.3$ & .83 \\
\hline $\mathrm{P}_{\mathrm{ETCO}_{2}}, \mathrm{~mm} \mathrm{Hg}$ & $4.8 \pm 0.4$ & $4.6 \pm 0.7$ & .35 \\
\hline $\mathrm{pH}$ & $7.44 \pm 0.04$ & $7.45 \pm 0.02$ & .41 \\
\hline $\mathrm{C}_{\mathrm{RS}}, \mathrm{mL} / \mathrm{cm} \mathrm{H}_{2} \mathrm{O}$ & $43.7 \pm 12.4$ & $44.2 \pm 11.1$ & .91 \\
\hline $\begin{array}{l}\text { Mean arterial pressure, } \\
\mathrm{mm} \mathrm{Hg}\end{array}$ & $96.3 \pm 12.6$ & $95.7 \pm 14.1$ & .91 \\
\hline Heart rate, beats/min & $81.3 \pm 17.1$ & $82.6 \pm 18.1$ & .84 \\
\hline $\mathrm{S}_{\overline{\mathrm{v}}_{2}}, \%$ & $75.8 \pm 9.4$ & $77.2 \pm 6.2$ & .64 \\
\hline$\dot{\mathrm{Q}}_{\mathrm{S}} / \dot{\mathrm{Q}}_{\mathrm{T}}$, mean $\pm \mathrm{SD} \%$ & $22.8 \pm 5.1$ & $20.8 \pm 5.6$ & .32 \\
\hline $\begin{array}{l}\text { Fluid balance, } \mathrm{mL} \text { in the } \\
\text { past } 24 \mathrm{~h}\end{array}$ & $-712.4 \pm 567.4$ & $-855.0 \pm 868.2$ & .60 \\
\hline $\begin{array}{l}\text { Values are mean } \pm \mathrm{SD} \\
\mathrm{RM}=\text { recruitment maneuver } \\
\mathrm{V}_{\mathrm{T}}=\text { tidal volume } \\
\dot{\mathrm{V}}_{\mathrm{E}}=\text { minute volume } \\
\mathrm{P}_{\text {plat }}=\text { plateau pressure } \\
\mathrm{P}_{\text {peak }}=\text { peak pressure } \\
\mathrm{P}_{\mathrm{ETCO}}=\text { partial pressure of end }-\mathrm{t} \\
\mathrm{C}_{\mathrm{RS}}=\text { quasistatic compliance of } \\
\mathrm{S} \\
\mathrm{S}_{\mathrm{V}_{2}}=\text { mixed venous oxygen satu } \\
\mathrm{Q}_{\mathrm{S}} / \mathrm{Q}_{\mathrm{T}}=\text { shunt fraction. }\end{array}$ & $\begin{array}{l}\mathrm{CO}_{2} \\
\text { respiratory system } \\
\text { ion }\end{array}$ & & \\
\hline
\end{tabular}

\section{Discussion}

To our knowledge this is the first prospective randomized study that evaluates the application of an RM before PDT in order to improve oxygenation in ALI patients. Our aim was to investigate the extent and duration of the effect on arterial oxygenation and to determine the utility and reliability of RM in this clinical setting. The major finding of this study was a significant improvement in arterial oxygenation after PDT in subjects who underwent RM. We used continuous positive airway pressure at $40 \mathrm{~cm} \mathrm{H}_{2} \mathrm{O}$ for 40 seconds, as shown by Lapinsky and colleagues, ${ }^{26}$ 10 min before PDT ( $1 \mathrm{~h}$ before RM) in 15 subjects. Oxygenation was improved 5 min after RM, worsened 5 min after PDT, and increased at $30 \mathrm{~min}$ after PDT; at all the stages $\mathrm{P}_{\mathrm{aO}}$ remained significantly higher than in the control group (see Figure). There were no changes in $\mathrm{F}_{\mathrm{IO}_{2}}$ or PEEP that might mask improvements in gas exchange due to RM. This effect was transient because, 6 hours after PDT, $\mathrm{P}_{\mathrm{aO}_{2}}$ values in the RM group returned similar to baseline values ( $1 \mathrm{~h}$ before $\mathrm{RM}$ ), but the control group (no $\mathrm{RM})$ did not achieve the basal values ( $1 \mathrm{~h}$ before $\mathrm{RM}$ ) 6 hours after PDT.
Although PDT is a safe procedure, ${ }^{27}$ hypoventilation, hypoxemia, and hypercarbia may occur during the procedure, especially in patients with lung injury. ${ }^{2}$ Also, our data showed a fall in $\mathrm{P}_{\mathrm{aO}_{2}}$ and a mild rising in $\mathrm{P}_{\mathrm{aCO}_{2}}$ in both groups 5 min after PDT, but the $\mathrm{P}_{\mathrm{aCO}}$ modifications were not statistically significant. In accordance with other studies, our data do not reveal any significant changes in $\mathrm{V}_{\mathrm{D}} / \mathrm{V}_{\mathrm{T}}$ or $\mathrm{P}_{\mathrm{aCO}}{ }{ }^{7,10}$ This can be explained by the fact that variations in $\mathrm{P}_{\mathrm{aCO}_{2}}$ and end-tidal partial pressure of $\mathrm{CO}_{2}$ would be proportionate to carbon dioxide production $\left(\dot{\mathrm{V}}_{\mathrm{CO}_{2}}\right)$ only after a prolonged washout time of blood (about 20-30 min) and tissue $\mathrm{CO}_{2}$ stores, while $\dot{\mathrm{V}}_{\mathrm{CO}_{2}}$ returns to the value corresponding to metabolic rate with the system at new steady state. ${ }^{28}$ Our blood samples were collected and $\mathrm{V}_{\mathrm{D}} / \mathrm{V}_{\mathrm{T}}$ was calculated. Alveolar recruitment and derecruitment seem to be time-dependent mechanisms, and increased levels of positive pressure may require prolonged application for full effect on lung volume to occur. ${ }^{10}$

The effectiveness of RM in reducing hypoxemia secondary to $\mathrm{AD}$ was reported in many studies. This process can be accomplished through a variety of methods, including sustained inflation at high pressure, intermittent sighs, and stepwise increases in PEEP or peak airway pressure.7,14 $\mathrm{RM}$ has been introduced as an important component of a lung-protective ventilation strategy in ALI-ARDS patients, where $\mathrm{AD}$ may occur during low- $\mathrm{V}_{\mathrm{T}}$ ventilation. ${ }^{11}$ Different settings of RM have been studied, with variable results. ${ }^{8-12}$ In these patients the utility of RM was also evaluated in specific conditions associated with hypoxygenation and $\mathrm{AD}$ (for example accidental disconnection from the ventilator, open-circuit endotracheal suctioning, endobronchial fiberoptic procedure, and ventilator malfunction requiring ventilator replacement).

Lapinsky and Mehta recommended that, following such events, RM can be performed. ${ }^{8}$ Dyhr and co-workers showed that an RM immediately following endotracheal suctioning was as an adjunct to PEEP, effective in rapidly counteracting the deterioration in $\mathrm{P}_{\mathrm{aO}_{2}}$ and lung volume derecruitment caused by endotracheal suctioning in ventilator treated patients with ALI/ARDS. ${ }^{16}$ Maggiore and coworkers studied endotracheal suctioning in ALI patients and showed the utility of an RM during endotracheal suctioning in counteracting $\mathrm{AD}$ and fall of oxygenation. ${ }^{17}$ Constantin and colleagues also demonstrated the effectiveness of a RM applied immediately after intubation in reducing short-term hypoxemia in hypoxemic critical ill patients. ${ }^{18}$ In these studies RM was always performed after the event associated with $\mathrm{AD}$, when it was already established; on the contrary in our study we applied RM before the event, in order to prevent hypoxia due to AD. Besides, the risk of adverse events was lower before PDT than after, because patients had more stable conditions. In fact, in the postoperative period, PDT may be associated with 
Table 3. Changes of the Main Respiratory and Hemodynamic Parameters of the 2 Groups at the Different Times of the Study

\begin{tabular}{|c|c|c|c|c|c|c|}
\hline & & Before RM & $\begin{array}{c}5 \mathrm{Min} \\
\text { After RM }\end{array}$ & $\begin{array}{c}5 \mathrm{Min} \\
\text { After PDT }\end{array}$ & $\begin{array}{c}30 \mathrm{Min} \\
\text { After PDT }\end{array}$ & $\begin{array}{c}6 \text { Hours } \\
\text { After PDT }\end{array}$ \\
\hline \multirow[t]{2}{*}{$\mathrm{P}_{\mathrm{aO}_{2}}, \mathrm{~mm} \mathrm{Hg}$} & $\mathrm{RM}$ & $222.6 \pm 33.4$ & $341.3 \pm 33.1 * \dagger$ & $260.7 \pm 35.4 * \dagger$ & $285.6 \pm 29.1 * \dagger$ & $226.3 \pm 24.8^{*}$ \\
\hline & No RM & $246.7 \pm 26.0$ & $245.5 \pm 26.7$ & $108.5 \pm 36.9$ & $188.4 \pm 21.4$ & $147.6 \pm 42.8$ \\
\hline \multirow[t]{2}{*}{$\mathrm{P}_{\mathrm{aCO}_{2}}, \mathrm{~mm} \mathrm{Hg}$} & $\mathrm{RM}$ & $42.5 \pm 4.9$ & $43.5 \pm 6.2$ & $50.6 \pm 10.2$ & $43.4 \pm 5.5$ & $41.5 \pm 5.4$ \\
\hline & No RM & $38.9 \pm 6.0$ & $40.2 \pm 9.2$ & $46.8 \pm 4.3$ & $38.5 \pm 4.8$ & $39.8 \pm 3.9$ \\
\hline \multirow[t]{2}{*}{$\mathrm{V}_{\mathrm{D}} / \mathrm{V}_{\mathrm{T}}, \%$} & $\mathrm{RM}$ & $51.2 \pm 7.5$ & $49.2 \pm 7.2$ & $51.1 \pm 12.3$ & $52.6 \pm 12.7$ & $50.7 \pm 5.5$ \\
\hline & No RM & $50.2 \pm 12.8$ & $50.9 \pm 17.8$ & $55.0 \pm 11.9$ & $51.7 \pm 13.7$ & $51.6 \pm 10.3$ \\
\hline \multirow[t]{2}{*}{ Cardiac output, L/min } & $\mathrm{RM}$ & $5.6 \pm 2.9$ & $5.1 \pm 1.9$ & & & \\
\hline & No RM & $5.4 \pm 2.4$ & $5.2 \pm 2.0$ & & & \\
\hline \multicolumn{7}{|c|}{$\begin{array}{l}* P<.01 \text { between the recruitment maneuver (RM) and no RM groups. } \\
\dagger P<.01 \text { with respect to before RM. } \\
\mathrm{V}_{\mathrm{D}} / \mathrm{V}_{\mathrm{T}}=\text { dead space fraction }\end{array}$} \\
\hline
\end{tabular}

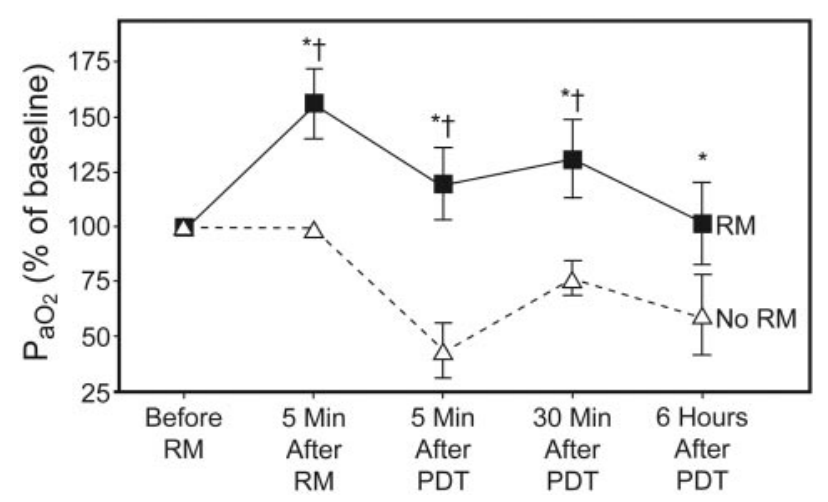

Figure. Percentage variations of $\mathrm{P}_{\mathrm{aO}}$ at the different times of the study among the 2 groups of subjects. Since we were interested in changes in oxygenation during the procedure, $\mathrm{P}_{\mathrm{aO}_{2}}$ values at the different times were normalized to the 1 hour before recruitment maneuver (RM) values. ${ }^{*} P<.01$ between groups (RM vs no $\left.R M\right)$. $\dagger P<.01$ with respect to 1 hour before RM in the RM group. PDT $=$ percutaneous dilational tracheostomy.

early and late complications, like bleeding and pneumothorax, which could represent a contraindication to RM. ${ }^{3}$

Although RM is generally well tolerated, sometimes several complications may occur. Hypotension (12\%) and desaturation (9\%) are the most frequent. Serious complications, including barotrauma and arrhythmia, are uncommon. ${ }^{7,29}$ Also bacterial translocation has been supposed but not clearly demonstrated. ${ }^{8}$ RM may impair hemodynamics by decreasing venous return and right ventricular preload, and by increasing pulmonary vascular resistance and right ventricular afterload ${ }^{19,29}$; however, these effects are very transient and after few minutes arterial pressure and cardiac output return to basal values. ${ }^{30}$

Our study did not reveal major complications. In particular, we did not observe any significant decrease in mean arterial pressure, stroke volume, or cardiac output after the RM. Only one subject needed interruption of RM due to severe hypotension (systolic arterial pressure $<90 \mathrm{~mm} \mathrm{Hg}$ ). To better interpret our results, some limitations need to be stressed. The number of subjects included in our study is relatively small because we selected only patients with ALI in the absence of hemodynamic instability and substantial arrhythmias. We believe that further evaluation in a larger randomized controlled clinical trial could be useful, including also patients with ARDS. The P-V curve procedure may have induced some recruitment that may have favored the no-RM group. On the contrary, use of $\mathrm{F}_{\mathrm{IO}_{2}}$ of 1.0 may have exacerbated derecruitment in the no-RM group, favoring the RM group. However, it is important to consider that use of high $\mathrm{F}_{\mathrm{IO}_{2}}$ is common during tracheostomy. Reduction of fall in $\mathrm{P}_{\mathrm{aO}_{2}}$ is not clinically related with a better patient outcome, but we think that the gain in $\mathrm{P}_{\mathrm{aO}}$ obtained after RM allows us to perform an invasive procedure such as PDT more safely, especially in high severity patients.

As we investigated a specific type of RM, it is possible that different results could be obtained by using other maneuvers. Besides, we applied RM only once and we did not increase PEEP after the maneuver. Six hours after PDT, $\mathrm{P}_{\mathrm{aO}_{2}}$ values in the RM group were similar to baseline values. Previous studies have proven that the positive effect on oxygenation due to RM is transient, ${ }^{7-9}$ so it could be appropriate to increase the PEEP level or repeat RM after PDT, in order to maintain the improvement in $\mathrm{P}_{\mathrm{aO}}$. Finally, evaluating alveolar recruitment only by gas exchange data may be a limitation of our study. In fact, arterial oxygenation is a complex physiologic parameter related to several factors, such as lung aeration, but also pulmonary blood flow, mixed venous saturation and cardiac output, whereas alveolar recruitment has a precise anatomical basis. ${ }^{31}$ 


\section{Recruitment Maneuver in Prevention of Hypoxia During Percutaneous Dilational Tracheostomy}

\section{Conclusions}

In conclusion, our study shows that application of RM before PDT acutely reduces fall in oxygenation associated with ventilator disconnection and use of bronchoscope. Moreover, it prevents $\mathrm{P}_{a}$ decrease below baseline values at 6 hours, confirming its utility in avoiding hypoxemia following such invasive procedures. However, this effect is transient if the maneuver is not repeated or followed by an adjustment of the PEEP level. In our experience, RM is safe and free from major complications. Further studies are required to determine if the RM preventing transient deterioration in oxygenation is associated with longer term improvement in outcomes.

\section{ACKNOWLEDGMENTS}

We are grateful to the personnel of the ICU department for the assistance in data collection for this study.

\section{REFERENCES}

1. De Leyn P, Bedert L, Delcroix M, Depuydt P, Lauwers G, Sokolov $\mathrm{Y}$, et al; Belgian Association of Pneumology and Belgian Assocation of Cardiothoracic Surgery. Tracheotomy: clinical review and guidelines. Eur J Cardiothorac Surg 2007;32(3):412-421.

2. Reilly PM, Anderson HL 3rd, Sing RF, Schwab WC, Bartlett RH. Occult hypercarbia. An unrecognized phenomenon during percutaneous endoscopic tracheostomy. Chest 1995;107(6):1760-1763.

3. Durbin CG Jr. Early complications of tracheostomy. Respir Care 2005;50(4):511-515.

4. Benini A, Rossi N, Maisano P, Marcolin R, Patroniti N, Pesenti A, Foti G. Translaryngeal tracheostomy in acute respiratory distress syndrome patients. Intensive Care Med 2002;28(6):726-730.

5. Meade MO, Cook DJ, Guyatt GH, Slutsky AS, Arabi YM, Cooper DJ, et al. Ventilation strategy using low tidal volumes, recruitment maneuvers, and high positive end-expiratory pressure for acute lung injury and acute respiratory distress syndrome: a randomized trial. JAMA 2008;299(6):637-645.

6. Rouby JJ, Lu Q. Bench-to-bedside review: adjuncts to mechanical ventilation in patients with acute lung injury. Crit Care 2005;9(5): 465-471.

7. Fan E, Wilcox ME, Browe RG, Stewart TE, Mehta S, Lapinsky SE, et al. Recruitment maneuvers for acute lung injury. A systematic review. Am J Respir Crit Care Med 2008;178(11):1156-1163.

8. Lapinsky SE, Mehta S. Bench-to-bedside review: recruitment and recruiting maneuvers. Crit Care 2005;9(1):60-65.

9. Meade MO, Cook DJ, Griffith LE, Hand LE, Lapinsky SE, Stewart TE, Killian KJ, Slutsky AS, Guyatt GH. A study of the physiologic responses to a lung recruitment maneuver in acute lung injury and acute respiratory distress syndrome. Respir Care 2008;53(12):14411449.

10. Foti G, Cereda M, Sparacino ME, DeMarchi L, Villa F, Pesenti A. Effects of periodic lung recruitment maneuvers on gas exchange and respiratory mechanics in mechanically ventilated acute respiratory distress syndrome (ARDS) patients. Intensive Care Med 2000;26: 501-507.

11. Grasso S, Mascia L, Del Turco M, Malacarne P, Giunta F, Brochard $\mathrm{L}$, et al. Effects of recruiting maneuvers in patients with acute respiratory distress syndrome ventilated with protective ventilatory strategy. Anesthesiology 2002;96(4):795-802.
12. Patroniti N, Foti G, Cortinovis B, Maggioni E, Bigatello LM, Cereda M, Pesenti A. Sigh improves gas exchange and lung volume in patients with acute respiratory distress syndrome undergoing pressure support ventilation. Anesthesiology 2002;96(4):788-794.

13. Piacentini E, Villagrá A, López-Aguilar J, Blach L. Clinical review: the implications of experimental and clinical studies of recruitment maneuvers in acute lung injury. Crit Care 2004;8(2):115-121.

14. Constantin JM, Jaber S, Futier E, Sayot-Constantin S, Verny-Pic M, Jung B, et al. Respiratory effects of different recruitment maneuvers in acute respiratory distress syndrome. Crit Care 2008;12(2):R50.

15. Rothen HU, Neumann P, Berglund JE, Valtysson J, Magnusson A, Hedenstierna G. Dynamics of re-expansion of atelectasis during general anaesthesia. Br J Anaesth 1999;82(4):551-556.

16. Dyhr T, Bonde J, Larsson A. Lung recruitment maneuvers are effective in regaining lung volume and oxygenation after open endotracheal suctioning in acute respiratory distress syndrome. Crit Care 2003;7(1):55-62.

17. Maggiore SM, Lellouche F, Pigeot J, Taille S, Deye N, Durrmeyer $\mathrm{X}$, et al. Prevention of endotracheal suctioning-induced alveolar derecruitment in acute lung injury. Am J Respir Crit Care Med 2003; 167(9):1215-1224.

18. Constantin JM, Futier E, Cherprenet AL, Chanques G, Guérin R, Cayot-Constantin $\mathrm{S}$, et al. A recruitment maneuver increases oxygenation after intubation of hypoxemic intensive care unit patients: a randomized controlled study. Crit Care 2010;14(2):R76.

19. Iannuzzi M, De Sio A, De Robertis E, Piazza O, Servillo G, Tufano R. Different patterns of lung recruitment maneuvers in primary acute respiratory distress syndrome; effects on oxygenation and central hemodynamics. Minerva Anestesiol 2010;76(9):692-698.

20. Valenza F. Do recruitment maneuvers simply improve oxygenation? Crit Care 2010;14(4):173.

21. Bernard GR, Artigas A, Bringham KL, Carlet J, Falke K, Hudson $\mathrm{L}$, et al. The American-European Consensus Conference on ARDS: definitions, mechanisms, relevant outcomes and clinical trial coordinations. Am J Respir Crit Care Med 1994;149(3 Pt 1):818824.

22. Brower RG, Morris A, MacIntyre N, Matthay MA, Hayden D, Thompson T, et al; ARDS Clinical Trials Network; National Heart, Lung, and Blood Institute; National Institutes of Health. Effects of recruitment maneuvers in patients with acute lung injury and acute respiratory distress syndrome ventilated with high positive end-expiratory pressure. Crit Care Med 2003;31(11):2592-2597. Erratum in: Crit Care Med 2004;32(3):907.

23. Serita R, Morisaki H, Takeda J. An individualized recruitment maneuver for mechanically ventilated patients after cardiac surgery. J Anesth 2009;23(1):87-92.

24. Boffelli S, Rossi C, Anghileri A, Giardino M, Carnevale L, Messina $\mathrm{M}$, et al. Continuous quality improvement in intensive care medicine. The GiViTi (Gruppo Italiano per la Valutazione degli Interventi in Terapia Intensiva) Margherita project: report 2005. Minerva Anestesiol 2006;72(6):419-432.

25. Levy P, Similowski T, Corbeil C et al. A method for studying the static volume-pressure curves of the respiratory system during mechanical ventilation. J Crit Care 1989;4:83-89.

26. Lapinsky SE, Aubin M, Mehta S, Boiteau P, Slutsky AS. Safety and efficacy of a sustained inflation for alveolar recruitment in adults with respiratory failure. Intensive Care Med 1999;25(11): 1297-1301.

27. Beiderlinden M, Groeben H, Peters J. Safety of percutaneous dilational tracheostomy in patients ventilated with high positive endexpiratory pressure (PEEP). Intensive Care Med 2003;29(6):944948. 
28. Taskar V, John J, Larsson A, Wetterberg T, Jonson B. Dynamics of carbon dioxide elimination following ventilator resetting. Chest 1995; 108(1):196-202.

29. Toth I, Leiner T, Mikor A, Szakmany T, Bogar L, Molnar Z. Hemodynamic and respiratory changes during lung recruitment and descending optimal positive end-expiratory pressure titration in patients with acute respiratory distress syndrome. Crit Care Med 2007; 35(3):787-793.
30. Garutti I, Martinez G, Cruz P, Piñeiro P, Olmedilla L, de la Gala F. The impact of lung recruitment on hemodynamics during one-lung ventilation. J Cardiothorac Vasc Anesth 2009;23(4):506-508.

31. Henzler D, Pelosi P, Dembinski R, Ullmann A, Mahnken AH, Rossaint R, Kuhlen R. Respiratory compliance but not gas exchange correlates with changes in lung aeration after a recruitment maneuver: an experimental study in pigs with saline lavage lung injury. Crit Care 2005;9(5):R471-R482.

This article is approved for Continuing Respiratory Care Education credit. For information and to obtain your CRCE

(free to AARC members) visit

www.rcjournal.com 